\title{
UM ESTUDO DE CASO COM ESTUDANTES EM CURSO FIC PRONATEC ENVOLVENDO CONHECIMENTOS SOBRE PROBLEMAS SOCIAIS E AMBIENTAIS
}

\author{
J.F.F. POUEY ${ }^{1}$ e L.F.S. LAROQUE ${ }^{2}$ \\ Instituto Federal de Educação, Ciência e Tecnologia Sul-riograndense ${ }^{1}$ \\ Centro Universitário Univates ${ }^{2}$ \\ Iflaroque@terra.com.br ${ }^{2}$
}

Artigo submetido em 06/03/2016 e aceito em 24/06/2019

DOI: $10.15628 /$ holos.2019.4222

\section{RESUMO}

As políticas públicas para a formação profissional tiveram significativo investimento no primeiro governo Dilma no Brasil e o Programa Nacional de Acesso ao Ensino Técnico e Emprego (Pronatec), alcançou a meta de oito milhões de matriculas em cursos técnicos de grau médio ou de formação inicial e continuada (FIC). O objetivo do estudo é identificar se a capacitação técnica dos cursos FIC foi desenvolvida juntamente com a formação social e política dos estudantes com vista aos conhecimentos dos problemas sociais e ambientais. A pesquisa é qualiquantitativa e os procedimentos metodológicos constitui-se na aplicação de questionários em uma amostragem com 10 estudantes do curso de capacitação ou FIC do Pronatec - área da construção civil de Mestre de Obras no Instituto Federal Sul-rio-grandense (IFSul), câmpus Pelotas, Rio Grande do Sul. Consultou-se documentos, tais como Projeto Político Pedagógico, matriz curricular, conteúdos programáticos e a legislação sobre o Pronatec, os quais foram analisados com base em autores que tratam da educação profissional, educação ambiental e construção civil e ambiente. Constatou-se que o curso propicia pouca quantidade de conhecimento sobre a problemática ambiental e fazem parte dos conteúdos somente de uma disciplina, enquanto deveriam ser trabalhados de maneira transversal.

PALAVRAS-CHAVE: Pronatec, educação técnica, construção civil, problemática social e ambiental.

\section{A CASE STUDY WITH STUDENTS ATTENDING A FIC PRONATEC COURSE IN SOCIAL AND ENVIRONMENTAL ISSUES}

\begin{abstract}
Public policies on professional development got significant investments in Dilma's first term. The socalled Programa Nacional de Acesso ao Ensino Técnico e Emprego (Pronatec) had eight million students enrolled in high school technical courses, besides early and continuing education ones (FIC). This study aims at identifying whether the technical qualification provided by the FIC courses was developed along with students' social and political education so that they could gain knowledge of social and environmental issues. This qualitative-quantitative research and its methodological procedures comprised the use of questionnaires with ten students attending the technical qualification course or
\end{abstract}

the FIC one, a part of the Pronatec in the area of civil construction at the Instituto Federal Sul-rio-grandense (IFSul), in Pelotas, Rio Grande do Sul state, Brazil. Several documents, such as the political-pedagogical plan, the syllabus, the contents of each discipline and the legislation regarding Pronatec, were analyzed in the light of authors that deal with professional education, Environmental Education, besides civil and environmental construction. The course was observed to provide little knowledge on environmental issues which have only been part of a single discipline, rather than belonging to a field of study which works on it as a whole.

KEYWORDS: Pronatec, technical education, civil construction, social and environmental issues 


\section{INTRODUÇÃO}

As transformações nas relações de produção e de mercado ditadas pelo capitalismo e ampliadas pela globalização cada vez mais tem suas repercussões nas relações sociais, sejam elas de trabalho ou de educação. Frigotto (2001, p. 72), salienta que estamos em um "tempo de ampliação do desemprego, da precarização do trabalho e de uma situação de permanente angústia e insegurança daqueles que, para sobreviver, têm apenas sua força de trabalho para vender".

Tratando-se da educação é possível contextualizá-la neste cenário, seja ela geral ou profissional, podemos ver a tecnologia e a ciência como instrumentos de legitimação da exclusão ou como a rede de fatores sociais, culturais e econômicos imprescindíveis para a emancipação do homem.

Durante muitos anos, a repetição de práticas consagradas sob o controle do professor era o que servia como educação profissional do operário para o mundo do trabalho, no entanto devido a globalização econômica e as modificações produtivas, não serve mais conceber o trabalhador como se fosse um "robô". Novos materiais, equipamentos e tecnologias exigem conhecimentos mais abrangentes do trabalhador, ou seja, necessita-se de indivíduos que além de desenvolver as atividades de produção, também possua uma educação básica consistente que visualize as questões sociais e produtivas, contemple a problemática ambiental, bem como conectada as transformações do mundo globalizado.

O Programa Nacional de Acesso ao Ensino Técnico e Emprego (Pronatec), lançado em 2011, através da lei no 12.513, de 26 de outubro, apresenta na primeira etapa (2011-2014), a meta de expansão da rede física dos Institutos Federais e matricular no Brasil 8 milhões de indivíduos nos cursos técnicos e de Formação Inicial e Continuada (FIC), as quais segundo o MEC foram plenamente atingidas. Delimitando para a pesquisa estudantes do curso de capacitação ou FIC do Pronatec do segundo semestre de 2014, dentro da área da construção civil de Mestre de Obras no Instituto Federal Sul-rio-grandense (IFSul), câmpus Pelotas, Rio Grande do Sul, o presente estudo tem como objetivo identificar se a capacitação técnica dos cursos FIC foi desenvolvida juntamente com a formação social e política dos estudantes com vista aos conhecimentos dos problemas sociais e ambientais.

\section{REVISÃO BIBLIOGRÁFICA}

\subsection{Educação profissional}

Com o intuito de um melhor entendimento do Pronatec, vale primeiramente revisitar os antecedentes da educação profissional no Brasil como política pública. A busca pela história da educação profissional no Brasil nos remete ao período colonial antes do trabalho manual ser praticado pelos escravos, época em que as camadas sociais tinham em seu cume a sociedade 
rural, após apareciam os artífices, os mecânicos, os tecelões, os indígenas e posteriormente os escravos. Como diz Rodrigues (2002, p. 51) "Aqueles que empregavam as mãos para viver "gozavam de certas prerrogativas sociais, talvez dadas pela extrema e direta necessidade desses pelas classes dominantes". Ainda segundo o autor, a formação de novos artífices acontecia nas próprias fazendas em oficinas rudimentares.

No entanto, a descoberta do ouro no final do século XVII em Minas Gerais, trouxe um intenso deslocamento de trabalhadores rurais de muitas Províncias do Brasil, bem como gente da Europa para atividades de exploração minerada na região das gerais. Conforme Garcia (2000) surgiram as Casas de Fundição e de Moeda e profissões ligadas ao metal, mas essa aprendizagem era destinada principalmente aos homens brancos, descendentes dos portugueses, muito embora a predominância da população fosse mestiça, filha de homens europeus com mulheres índias e negras.

No Brasil Colonial, segundo Fausto (1994), as atividades industriais por meio de manufaturas são incentivadas pelas medidas pombalinas. Entretanto, com o governo de D. Maria I que assume o trono português, no Brasil as manufaturas ou qualquer iniciativa industrial, a partir de 1797, passam a ser terminantemente proibida. Salienta-se também que as atividades manuais ficaram restritas aos escravos e como tal, passam a serem desprezadas e discriminadas pelos homens livres de qualquer classe social, inclusive "[...] daqueles que estavam socialmente mais próximos dos escravos: mestiços e brancos pobres" (CUNHA, 2000, p. 90).

Neste sentido, Garcia (2000), destaca que para os centros de aprendizagem de ofícios dos Arsenais da Marinha no Brasil havia uma patrulha que andava na noite, após o toque de recolher, recrutando homens livres para serem aprendizes. Sobre isto temos:

Desde os tempos coloniais, quando um empreendimento manufatureiro de grande porte, como os
arsenais de marinha, por exemplo, exigia um contingente de trabalhadores não disponíveis, o
Estado coagia homens livres a se transformarem em artífices. Não fazia isso, decerto, com
quaisquer homens livres, mas com aqueles que social e politicamente não estavam em condições
de opor resistência. Como na formação das guarnições militares e navais, prendiam-se os
miseráveis. Procedimentos semelhantes eram adotados para com os menores destinados à
aprendizagem de ofícios: os órfãos, os abandonados, os desvalidos, que eram encaminhados pelos
juízes e pelas Santas Casas de Misericórdia aos arsenais militares e de marinha, onde eram
internados e postos a trabalhar como artífices, até que, depois de um certo número de anos,
escolhessem livremente onde, como e para quem trabalhar (CUNHA, 2000, p. 91).

No século XIX o alvará de 1을 de abril de 1808, permitiu o livre estabelecimento de fábricas e manufaturas no Brasil, buscando "promover e adiantar a riqueza nacional, e sendo um dos mananciais dela as manufaturas e a indústria que multiplicam e melhoram e dão mais valor aos gêneros e produtos da agricultura e das artes" (CUNHA, 2000, p.91). De acordo com o autor em questão, com a vinda da Família Real para Brasil é que D. João VI, em 1809, cria o Colégio das Fábricas para abrigar os órfãos da Casa Pia de Lisboa que vieram na mesma frota juntamente com artífices que lhes ensinavam os ofícios. Também em 1809, conforme Cunha (2000, p. 91), temos 
"mesmo não sendo o primeiro estabelecimento de ensino profissional no Brasil, nem mesmo o que abrigou órfãos com esse propósito, ele foi a referência para os outros que vieram a ser instalados".

Na década de 40 do século XIX foram construídas em capitais das províncias dez Casas de Educandos e Artífices. Corroborando com a questão Cunha (2000, p. 91), informa que "[...] adotaram o modelo de aprendizagem de ofícios vigente no âmbito militar, inclusive os padrões de hierarquia e disciplina".

Na segunda metade do século XIX, ainda de acordo com Cunha (2000), nobres, fazendeiros, comerciantes, bem como as autoridades organizaram sociedades civis, cujo objetivo além de amparar os órfãos consistia em ministrar ensino de artes e ofícios. Algumas dessas sociedades criaram e mantiveram liceus de artes e ofícios como, por exemplo, a Sociedade Propagadora das Belas Artes, mantenedora do Liceu de Artes e Ofícios do Rio de Janeiro.

A Sociedade Propagadora das Belas Artes mantenedora do Liceu de Artes e Ofícios e da Faculdade Bethencourt da Silva, foi fundada em 23 de novembro de 1856, no Rio de Janeiro, pelo arquiteto Francisco Joaquim Bethencourt da Silva.

Paralelamente à fundação da SPBA foi criado o Liceu de Artes e Ofícios onde os artesões, operários e demais cidades pudessem estudar à noite a fim de aprender noções de desenho geométrico, industrial, artístico e arquitetônico e os princípios das ciências aplicadas às artes livres (PORTAL do LICEU DE ARTES E OFÍCIOS, s.d. texto digital).

Da mesma maneira, outros Liceus de Artes e Ofícios foram criados, tais como o de Salvador, em 1872, o de Recife, em 1880, o de São Paulo, em 1882, o de Maceió, em 1884 e o de Ouro Preto, em 1886.

Dentro do contexto da educação profissional, nos primeiros tempos do Brasil colônia, nos parece não haver uma resistência tão expressiva em relação ao trabalho manual pelos colonizadores. Entretanto, no momento em que passou a ser atividade dos escravos, todo e qualquer homem livre procurava se afastar das atividades braçais.

No início do século XIX, a partir do Colégio das Fábricas, foram criadas outras escolas para órfãos e homens livres desvalidos da sorte, as chamadas Casas de Educandos e Artífices e os Liceus de Artes e Ofícios. Todas empenhadas em ensinar o trabalho manual, mas sem a preocupação de escolarizar academicamente os educandos, o vez que este ensino destinava-se aos homens livres de posse.

Na República, a educação profissional iniciou na primeira década do século $X X$, através do decreto no 7.566, de 23 de setembro de 1909, pelo então presidente Nilo Peçanha, que criou nas capitais da União as Escolas de Aprendizes e Artífices (CUNHA, 2000).

Nos anos quarenta, sob a presidência de Getúlio Vargas, acontece a criação do Sistema S, primeiramente, em 1942, com o Serviço Nacional de Aprendizagem Industrial (SENAI) e, em 1946, com o Serviço Nacional de Aprendizagem Comercial (SENAC). Dessa maneira o governo deixa a 
qualificação profissional mais a critério do Sistema $S$, mesmo que financiado com recursos públicos (BIAGINI, 2005).

Ao longo do tempo as Escolas de Aprendizes e Artífices, sofrem modificações em suas estruturas e nomenclaturas, mas continuam a manter a característica inicial de escolas técnicas. Em 29 de dezembro de 2008, através da Lei no 11.892 estas instituições são transformadas em Institutos Federais de Educação, Ciência e Tecnologia (IFs), devendo ainda manter um mínimo de $50 \%$ de suas vagas para os cursos técnicos de nível médio integrada e para o público de Educação de Jovens e Adultos (EJA), mas ainda agregando cursos de licenciatura, bacharelado, graduação, pós-graduação, mestrados e cursos de Formação Inicial e Continuada (FIC).

Em resposta a necessidade de preparar o trabalhador brasileiro para novas tecnologias que surgiam junto com o crescimento industrial, o governo criou, através do Decreto n ㄴ 53.324, de 18 de dezembro de 1963, um plano emergencial, o Programa Intensivo de Preparação de Mão-deObra Industrial (PIPMOI). Segundo Machado e Garcia (2013, p. 48) o programa previsto inicialmente para funcionar por 20 meses acabou sendo mantido por 19 anos, "executando projetos governamentais até o ano de 1982".

De acordo com Santos (2003, p. 80) “O PIPMOI foi planejado junto à Diretoria do Ensino Industrial (DEI) no Ministério da Educação, recebendo verbas do Ensino Profissionalizante. Foi transferido para o Ministério do Trabalho em 1975, daí saindo seus recursos". Em 1972, o Decreto no 70.882 renomeia o programa para Programa Intensivo de Preparação de Mão-de-Obra (PIPMO) ampliando os seus cursos para o setor primário (agricultura) e terciário (comércio e serviços).

De acordo com Campos (2012), temos em 1996, durante o governo de Fernando Henrique Cardoso (FHC) ${ }^{1}$, a criação do Plano Nacional de Qualificação do Trabalhador (PLANFOR) que tinha como objetivo a qualificação ou requalificação de pelo menos $20 \%$ da população economicamente ativa (PEA) e a partir de 1999, com recursos do Fundo de Amparo ao Trabalhador (FAT).

Numa comparação da situação histórica do PIPMOI e do PLANFOR, Santos salienta:

O PIPMOI, então, constituiu-se em um quadro de emprego, de condução do trabalhador que frequentou algum curso de qualificação profissional para uma determinada vaga de emprego. 0 PLANFOR, por sua vez, emerge em um quadro de empregabilidade, quando a formação não garante uma vaga no mercado de trabalho (SANTOS, 2003, p. 63).

Posteriormente, no governo de Luís Inácio da Silva (LULA) ${ }^{2}$ foi instituído, sob a administração do Ministério do Trabalho e Emprego (MTE), o Plano Nacional de Qualificação (PNQ), que dividido em três setores pretendia abranger a totalidade da formação profissional. No entanto, paralelamente, o Ministério da Educação e Cultura (MEC), também oferecia programas para a formação profissional como: o Programa Nacional de Integração da Educação Básica com a

${ }^{1}$ Fernando Henrique Cardoso (FHC) - governo de 1999 a 2002.

${ }^{2}$ Luís Inácio da Silva (LULA) - $1^{\circ}$ governo de 2003 a 2006, $2^{\circ}$ governo de 2007 a 2010. 
Educação Profissional na Modalidade de Educação de Jovens e Adultos (PROEJA); o Programa Nacional de Inclusão de Jovens (PROJOVEM) e o Brasil Profissionalizante, de maneira que muitas vezes os programas do MTE e do MEC competiam entre si quando o público atingido era o mesmo para os dois (CAMPOS, 2012).

Em 2011 o governo Dilma³, através da Lei no 12.513/2011, cria o Programa Nacional de Acesso ao Ensino Técnico e Emprego (PRONATEC) sob a coordenação do MEC. É um programa ambicioso com objetivo de atingir 8 milhões de matriculas em cursos técnicos ou de formação inicial e continuada (FIC), além de um acréscimo significativo na infraestrutura da rede federal de ensino (Institutos Federais de Educação, Ciência e Tecnologia - IFs), aumentando de 354 para 562 unidades até 2014, conforme pode-se observar no Gráfico 1, pretendendo dessa maneira expandir, interiorizar e democratizar a oferta de cursos de educação profissional e tecnológica no Brasil.

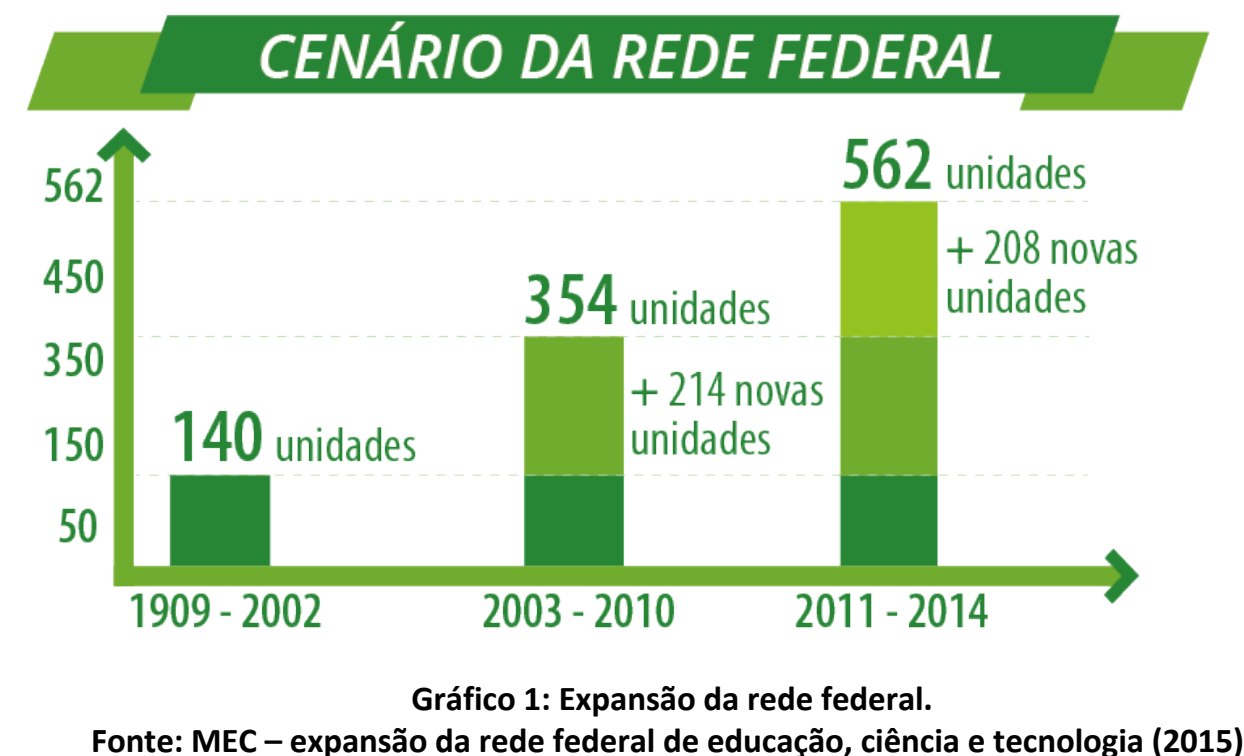

De acordo com o MEC (2015), com o investimento de $R \$ 3,3$ bilhões de reais entre 2011 a 2014, atingiu-se no território Brasileiro o montante de 562 unidades de programas em funcionamento. Esse parecia ser o plano que organizaria a educação técnica no Brasil, conforme segue:

[...] poder-se-ia entender o Pronatec como o sucessor dos programas de qualificação profissional do governo federal, porém, o que se verifica é a continuidade desarticulada de ações como o Proeja, o Projovem e o PNQ (o Brasil Profissionalizado foi desativado).

[...] o pagamento de bolsas de qualificação em programas como o Pronatec, boa parte de seu público que se enquadra também como alvo do Projovem pode neste programa usufruir de tal benefício, mostrando o problema da competição (CAMPOS, 2012, p. 7).

${ }^{3}$ Dilma Rousseff $-1^{\circ}$ governo de 2011 a 2014. 
Costa (2015), ao analisar os números das vagas ofertadas pelo Pronatec na Bolsa-Formação em 2013 apresenta aspectos bastante interessantes como: "[...] das 1.548.013 vagas ofertadas na Bolsa Formação, o percentual de $80 \%$ ou 1.238 .410 vagas foram registradas em cursos na modalidade FIC". Mais ainda:

Embora tanto instituições públicas como privadas estejam aptas a ofertar vagas no âmbito do PRONATEC, são o SENAI, O SENAC, O SENAT e o SENAR os maiores executores do programa. Considerando apenas as vagas ofertadas no âmbito da BolsaFormação, juntas, tais entidades foram responsáveis por $70,45 \%$ das vagas em 2013 , enquanto as demais instituições privadas respondem 9,59\% da oferta e a rede pública por apenas 19,9\% (COSTA, 2015, p. 98).

Também Lima (2012), tem uma visão cética do programa no que se refere a transferência de recursos públicos para empresas privadas tanto na aquisição dos cursos quanto nos financiamentos para os alunos, quando nas considerações finais de seu artigo afirma:

Com o Pronatec, o governo brasileiro completa o ciclo da privatização, precarização e aligeiramento da formação técnica de nível médio. O que antes era apenas enunciado, explicitamente torna a educação uma atividade central no processo de transferência de recursos públicos na tentativa de contenção da crise estrutural do capital (LIMA, 2012, p. 15).

O Pronatec divide seus cursos de capacitação ou FIC em eixos tecnológicos, entre eles apresenta-se o de infraestrutura, subdividido em duas áreas: construção civil e transporte. Na área da construção civil está o curso que obtemos as informações para este estudo, no intuito de verificar se esses cursos estão realmente preparando os alunos conforme a apresentação do MEC Pronatec, principalmente no que se refere a formação de um sujeito com respeito ao ser humano e ao ambiente.

Compreende tecnologias relacionadas à construção civil e ao transporte. Contempla ações de planejamento, operação, manutenção, proposição e gerenciamento de soluções tecnológicas para infraestrutura. Abrange obras civis, topografia, transporte de pessoas e bens, mobilizando, de forma articulada, saberes e tecnologias relacionadas ao controle de trânsito e tráfego, ensaios laboratoriais, cálculo e leitura de diagramas e mapas, normas técnicas e legislação. Características comuns deste eixo são a abordagem sistemática da gestão da qualidade, ética, segurança, viabilidade técnico-econômica e sustentabilidade (MEC Pronatec, 2013)4.

A apresentação do eixo tecnológico de Infraestrutura no Guia Pronatec de Cursos FIC, é enfática ao afirmar que esses cursos têm uma organização curricular que por sua vez "contempla

${ }^{4}$ Apresentação do eixo tecnológico de Infraestrutura (Guia Pronatec de Cursos FIC). 
estudos sobre ética, empreendedorismo, normas técnicas e de segurança, redação de documentos técnicos, educação ambiental, raciocínio lógico, formando técnicos que trabalhem em equipes com iniciativa, criatividade e sociabilidade" (MEC Pronatec, 2013).

A educação profissional no início da república tinha o mesmo cunho da educação do período anterior, cuja preocupação era evitar a marginalização que acompanhava os pobres, conforme podemos observar no argumento do Decreto no 7.566 de 1909, o qual “[...] não só habilitar os filhos dos desfavorecidos da fortuna com o indispensável preparo technico e intelectual, como fazê-los adquirir hábitos de trabalho profícuo, que os afastaria da ociosidade ignorante, escola do vicio e do crime"(MEDEIROS NETA, NASCIMENTO; RODRIGUES, 2012, p.97).

Dessa maneira, a educação profissional continuava a ser um ensino de trabalho manual distanciado da formação acadêmica. Somente em 1959, a Lei no 3.552 traz as primeiras articulações entre o ensino técnico e o propedêutico.

\subsection{Educação Ambiental}

Mesmo com a legislação da Política Nacional do Meio Ambiente, de 31 de agosto de 1981, que por sua vez prevê em seus princípios a Educação Ambiental, somente através da Lei no 9.795 de 27 de abril de 1999 (a qual dispõe sobre a educação ambiental, institui a Política Nacional de Educação Ambiental e dá outras providências), é que a educação ambiental passa a efetivamente ser instituída no Brasil. Os dois primeiros artigos da legislação indicam onde a educação ambiental deve estar presente:

Entende-se por educação ambiental os processos por meio dos quais o indivíduo e a coletividade constroem valores sociais, conhecimentos, habilidades, atitudes e competências voltadas para a conservação do meio ambiente, bem de uso comum do povo, essencial à sadia qualidade de vida e sua sustentabilidade (BRASIL, Lei no 9.795/1999, art. 1ㅇ).

A educação ambiental é um componente essencial e permanente da educação nacional, devendo estar presente, de forma articulada, em todos os níveis e modalidades do processo educativo, em caráter formal e não-formal (BRASIL, Lei no 9.795/1999, art. 2º).

De maneira singular Grün (2002), faz referência a educação ambiental, considerando que para ela ocorrer, supõe-se também a existência de uma educação não-ambiental, e neste sentido questiona a respeito de como "[...] podemos ter uma educação não-ambiental se desde o dia do nosso nascimento até o dia da nossa morte vivemos em um ambiente (GRÜN, 2002, p. 20). A partir disso o autor complementa que a necessidade do predicado ambiental à educação é porque a educação tem suas bases filosóficas no Cartesianismo e dessa forma parece ser desenvolvida fora de um ambiente. Por fim conclui que o ambiente ser inserido no conhecimento é necessário que respeitemos a "outridade da Natureza".

Também Gutiérrez e Prado nos trazem para a realidade de que somos parte da natureza ambiental e vivemos e aprendemos ou ensinamos em um ambiente. 
A pedagogia da cidadania ambiental da era planetária extrapola, em consequência, os estreitos limites da educação tradicional centrada na lógica da competição e acumulação, e na produção ilimitada de riqueza sem considerar os limites da natureza e as necessidades dos outros seres do cosmos.

Um aspecto básico da planetariedade é sentir e viver o fato de que fazemos parte constitutiva da Terra: esse ser vivo e inteligente que pede de nós relações planetárias, dinâmicas e sinérgicas (GUTIÉRREZ; PRADO, 2008, p. 38).

Sendo assim, compartilhamos a concepção de que a educação ambiental deve estar inserida em qualquer tipo de educação, não como uma disciplina, mas sim dentro de todas as disciplinas, em todos os níveis e modalidades do processo educativo formal ou não-formal, conforme a Lei no 9.795/1999.

No entanto, mesmo sabendo da necessidade da educação ambiental dentro de qualquer tipo de educação, observamos que a falta de uma formação continuada para os responsáveis pela educação, os professores, tem ainda mantido um ensinamento "bancário" e não uma educação questionadora, uma educação emancipadora, enfim uma educação que conscientize os estudantes da grande responsabilidade social que temos com o planeta.

\subsection{Construção Civil e Ambiente}

A humanização da espécie homem foi fazendo a sua evolução e a sua desnaturalização, passando a compreender que a natureza estava disposta para ser usada e explorada a seu bel prazer. Dentro dessa visão a evolução aprimorava seus conhecimentos e a busca por melhores condições de vida incluindo segurança, conforto, estética e fez da construção civil (CC) um importante segmento de transformação da natureza e da civilização.

A construção civil é uma atividade de fundamental importância na constituição das necessidades do homem e no benefício da civilização, independentemente do modo de produção em que se desenvolve. Devido a esta importância e interferência que provoca na sociedade, precisa ser repensada, principalmente no Brasil, onde o desemprego, subemprego e a distribuição de renda são problemas sociais crônicos (POUEY, 2012, p. 79).

Mas, por outro lado, enquanto a construção civil traz benefícios para o homem, ela também se apresenta como uma vilã no que diz respeito ao ambiente. Ceotto (2008), apresenta alguns fatores do impacto desta atividade no meio ambiente, como por exemplo:

- Na produção da maior parte dos insumos usados na CC o consumo de energia e liberação de $\mathrm{CO} 2$ é enorme;

- A produção de cimento é responsável por $8 \%$ a 9\% do CO2 emitido no Brasil; 
- Na construção e reforma se produzem anualmente perto de $400 \mathrm{~kg}$ de entulho por habitante, volume quase igual ao do lixo urbano;

- No mundo $40 \%$ da energia produzida é utilizada na operação dos edifícios;

- No Brasil essa operação consome $50 \%$ da energia elétrica e $20 \%$ do total de energia produzida;

- A CC gera de $35 \%$ a $40 \%$ de todo resíduo produzido na atividade humana.

Outros autores apresentam índices mais alarmantes. Mendes (2013), por exemplo, informa que internacionalmente entre $40 \%$ a $75 \%$ dos recursos naturais são consumidos pela construção civil, e mais, segundo o Conselho Internacional da Construção (CIB), a geração de resíduos da construção civil anunciada por Ceotto (2008) como de 35\% a 40\%, atualmente já passa dos $50 \%$ do total de resíduos produzidos por atividades humanas.

Considerando os índices alarmantes que são apresentados pelos autores, e a responsabilidade que temos com o ambiente, os profissionais da educação técnica em todas as áreas, mas nesse caso na área da construção civil, tem a responsabilidade de levar aos seus alunos o conhecimento das implicações de seus serviços com o ambiente, tentando dessa maneira conscientiza-los de que podem ser um multiplicador no que diz respeito a preservar a natureza.

\section{METOdOLOGIA}

$\mathrm{Na}$ intenção de buscar a percepção que alunos, de cursos FIC dentro da área da construção civil do Pronatec, possuem sobre as questões ambientais após o curso, foi realizada esta investigação de campo planejada, exploratória e metodológica numa abordagem qualiquantitativa e indutiva.

A pesquisa foi realizada com uma turma do curso de Mestre de Obras, do Instituto Federal de Educação, Ciência e Tecnologia Sul Rio Grandense (IFSul), no campus de Pelotas, estado do Rio Grande do Sul. Com uma carga horaria de 300 horas o curso teve início em setembro de 2014 com um número total de 20 alunos e encerrou no dia 23 de dezembro de 2014 formando 13 alunos. Na última semana do referido curso foi aplicado o questionário com questões abertas e fechadas para dez alunos ( $100 \%$ dos presentes) que representaram uma amostra de $77 \%$ dos formandos.

Os participantes da pesquisa, após esclarecidos dos objetivos do estudo e de responder o instrumento, assinaram o Termo de Consentimento Livre e Esclarecido (TCLE), concordando com a participação e com a garantia de que sua identidade será preservada. Neste trabalho tomamos como amostragem 10 alunos, os quais serão identificados como: E1, E2, E3, E4, E5, E6, E7, E8, E9 e E10.

A coleta de dados levantou a percepção que os entrevistados têm sobre ambiente, da problemática ambiental e da abrangência destas questões, tanto antes do curso como no sentido do que o curso agregou para cada um dos estudantes. Também se pesquisou documentos como: Projeto Político Pedagógico (PPC); matriz curricular e os conteúdos com vista a identificar a 
formação de estudantes críticos em relação as questões ambientais, mas também preocupados com os problemas sociais e políticos.

Feito a coletas os dados foram organizados e tabulados em função das variáveis para termos uma análise quantitativa dos mesmos. As questões abertas foram analisadas sob uma visão subjetiva de maneira que junto à pesquisa bibliográfica viabilizou uma análise qualitativa das informações. Dessa maneira com a interpretação dos dados qualitativos e quantitativos resultou uma análise descritiva que se encontra apresentada nos resultados, discussão e conclusão deste estudo.

\section{RESULTADOS E DISCUSSÕES}

A pesquisa foi dividida em duas partes, sendo que a primeira era referente a dados de identificação dos entrevistados e a segunda diz respeito a três aspectos fundamentais e distintos sobre a temática ambiental, que são: os conhecimentos que os pesquisados possuem sobre o ambiente e sua problemática; o que os mesmos consideraram sobre a abordagem desse tema durante as disciplinas do curso; e por fim as observações e sugestões dos participantes sobre o ambiente e a sustentabilidade.

A primeira parte da pesquisa, que se refere aos dados de identificação dos entrevistados a tabulação demonstrou que do universo de dez estudantes todos são naturais de Pelotas, com idades entre 31 e 60 anos, portanto trata-se de pessoas que estão ou estiveram incluídas no mundo do trabalho. Quanto a escolaridade, nove responderam as questões e um se absteve. Desses nove todos cursaram escola pública, sendo que quatro concluíram o ensino fundamental e cinco o ensino médio.

Morin (2003) no prefacio de sua obra "A cabeça bem-feita" apresenta uma análise relevante dos termos ensino e educação:

A bem dizer, a palavra "ensino" não me basta, mas a palavra "educação" comporta um excesso e uma carência. Neste livro, vou deslizar entre os dois termos, tendo em mente um ensino educativo. A missão desse ensino é transmitir não o mero saber, mas uma cultura que permita compreender nossa condição e nos ajude a viver, e que favoreça, ao mesmo tempo, um modo de pensar aberto e livre (MORIN, 2003, p. 11).

Com base nesse pensamento e ainda segundo Freire (1987, p. 39) "ninguém educa ninguém, ninguém educa a si mesmo, os homens se educam entre si, mediatizados pelo mundo". Considerando esta perspectiva, a segunda parte da pesquisa dedicou-se primeiramente ao levantamento dos conhecimentos ou entendimentos que os estudantes possuíam antes do curso sobre as questões ambientais e posteriormente sobre a abordagem dessa temática pelo curso. Para tanto, essa parte do trabalho foi dividida em três aspectos, assim determinados: 
- 10 aspecto: quanto ao entendimento dos entrevistados do ambiente e de sua problemática - $90 \%$ entendem que as atividades humanas interferem no meio ambiente (Gráfico 2), enquanto que $80 \%$ não veem a preocupação das pessoas com o aspecto de conservar espaços públicos ou mesmo particulares vazios, livres de lixo ou entulho.

No seu entendimento, os homens com suas atividades, interferem no meio ambiente?

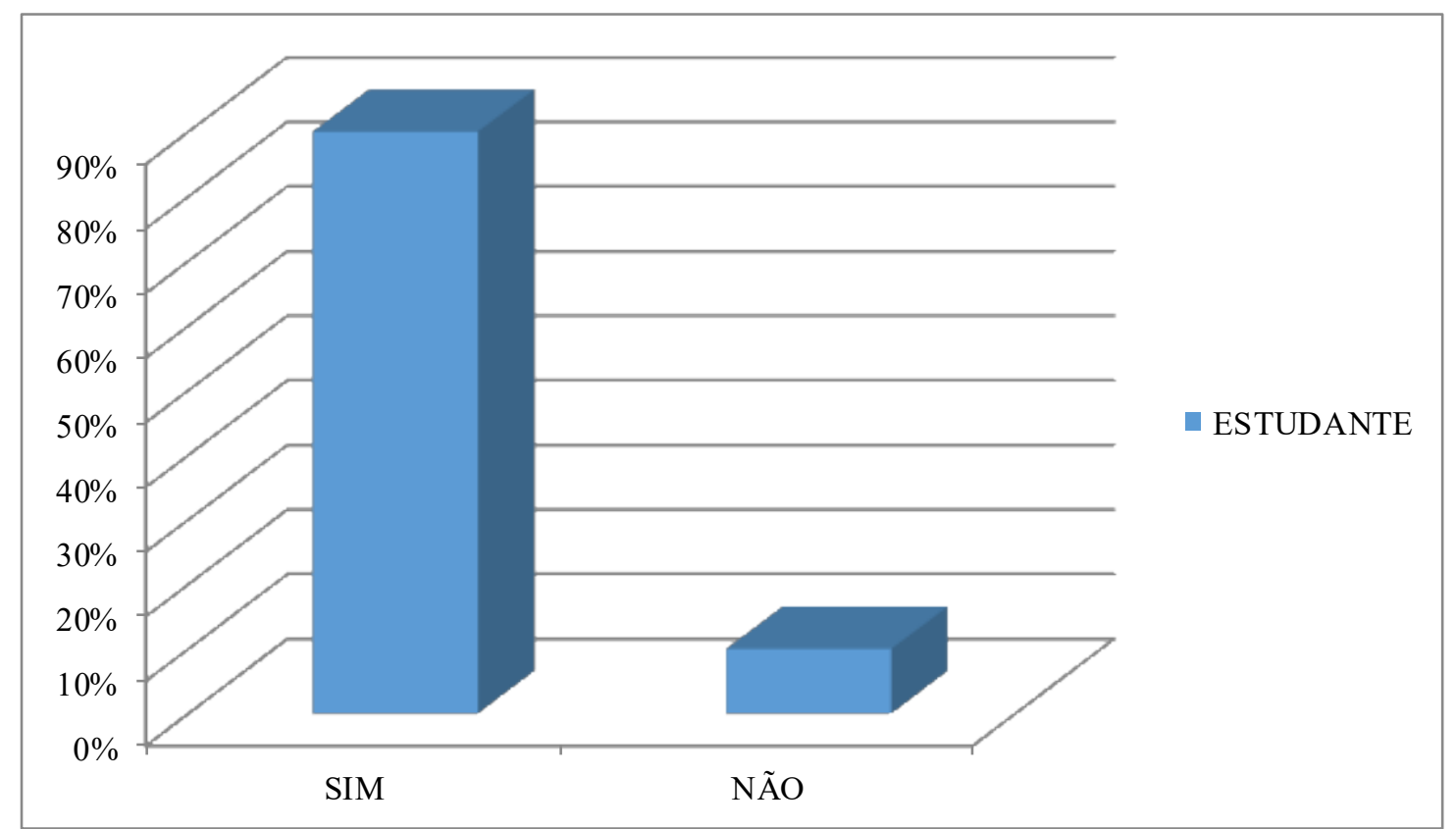

Gráfico 2: Percentual dos entrevistados sobre intervenção das atividades humanas no ambiente. Fonte: Autor (2016).

- 2o aspecto: esse momento levou os entrevistados a refletirem sobre o curso e abordagem das questões ambientais dentro das diversas disciplinas que fizeram parte da sua qualificação. Embora $50 \%$ dos entrevistados considerem que o curso Ihes deu conhecimentos sobre ambiente, saúde e sustentabilidade que vão servir para contribuir com a comunidade em geral (Gráfico 3), 70\% dos entrevistados não entendeu como suficiente esta abordagem (Gráfico 4).

Agora, ao final do curso, você considera que aprendeu coisas sobre ambiente, sustentabilidade, saúde, etc. que lhe permitam contribuir para a sua comunidade? 


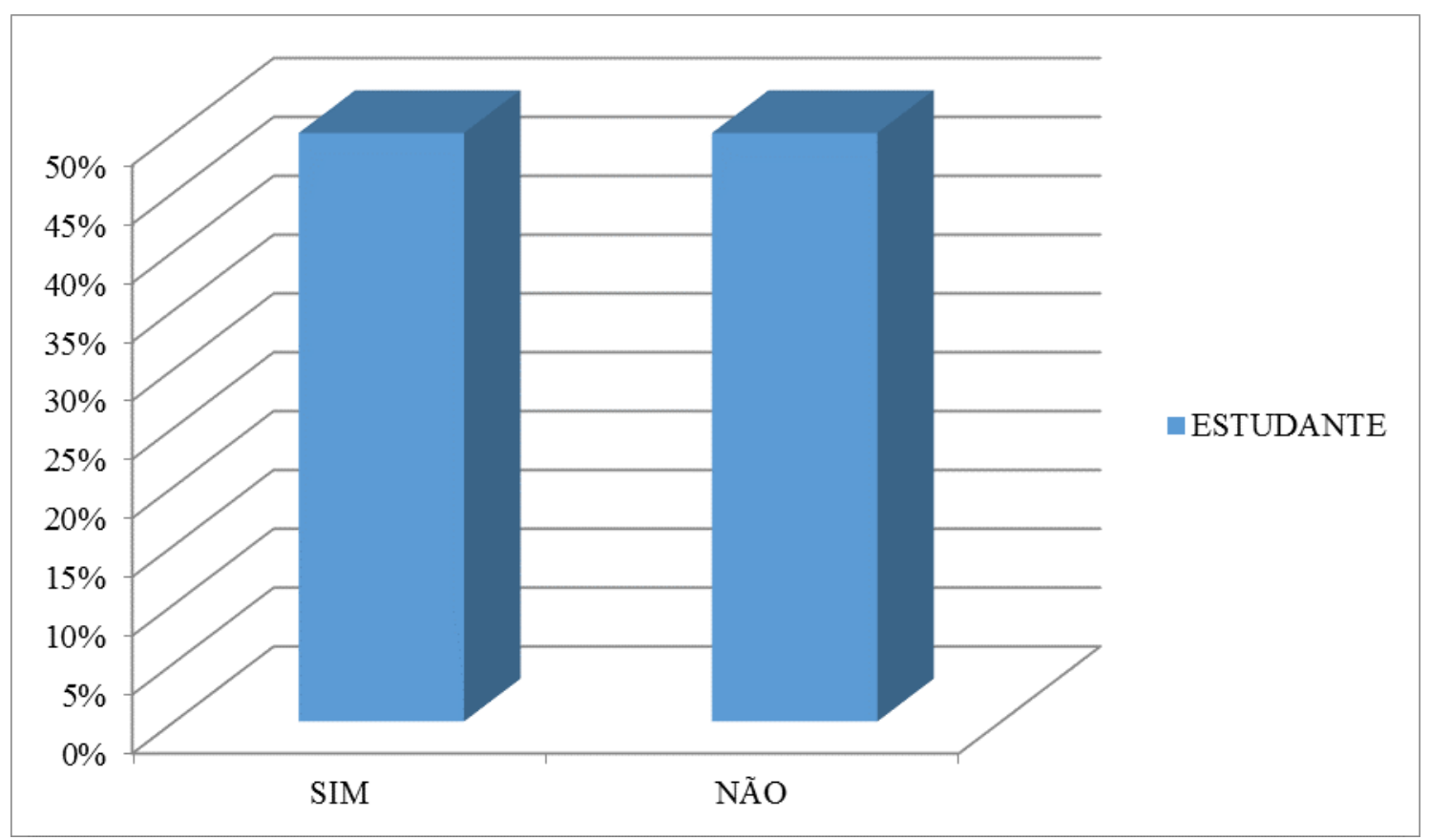

Gráfico 3: Percentual que considerou que os conhecimentos do curso lhe permitirão contribuir com a comunidade. Fonte: Autor (2016).

No seu entendimento o curso abordou o suficiente sobre os problemas ambientais?

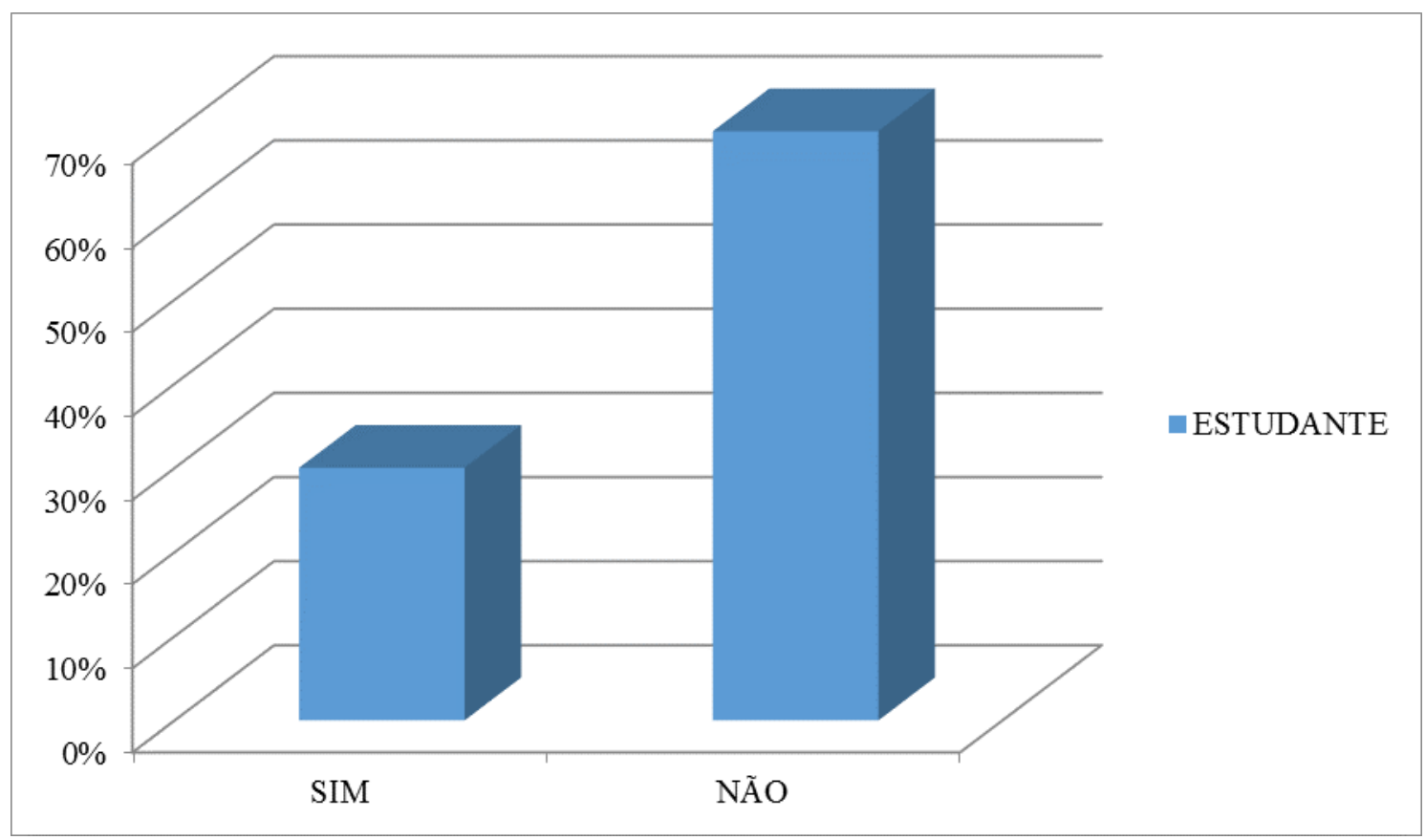

Gráfico 4: Percentual sobre o que o Curso abordou sobre problemas ambientais.

Fonte: Autor (2016).

- 3o aspecto: nessa parte do trabalho, solicitou-se que os entrevistados se manifestassem sobre algumas perguntas, sendo assim possível captar subjetivamente seus conhecimentos a respeito da construção civil como uma atividade que mesmo bem gerenciada é uma geradora de problemas ambientais de 
altíssima magnitude. Desse entendimento dos pesquisados podemos identificar alguns aspectos relevante para o estudo, conforme apresentamos e analisaremos a seguir:

Diante das questões descritivas do instrumento respondidas pelos estudantes, identificouse aspectos nas respostas que vale destacar. Corrobora para questão a pesquisa bibliográfica, os conteúdos programáticos e nos demais documentos tanto do curso como da própria legislação.

Ao analisarmos a primeira questão - "Você acredita que a construção civil é um gerador de problemas ambientais? Liste os problemas que você visualiza". Encontramos na maioria das respostas (60\%) a problemática com os resíduos (entulhos) descartados de maneira incorreta. Dentre as respostas salientamos a visão mais abrangente da problemática ambiental causada pela construção civil: "depósito de entulho em local inadequado, obras mal projetadas que geram alagamento urbano, retirada de materiais da própria natureza" (E4, 2014, p. 5).

De certa maneira, dentro da diversidade de respostas, conseguimos abranger: descarte de materiais em locais públicos; limpeza de materiais, resíduos e poeira dos materiais sobre gramados; desagregamento e mistura de materiais no solo; lixos recicláveis não reaproveitados; queima de lixo no canteiro de obras; falta de recursos para manter o canteiro limpo e a retirada de matéria prima para a fabricação dos materiais.

Essas respostas demostram que os trabalhadores do canteiro de obra, de certa maneira, conhecem os problemas que o uso ou descarte indevido dos materiais de construção causam no ambiente, e entendemos que isso ocorre por ser um problema visível. No entanto, eles não relacionam que esse contexto leva a uma série de desdobramentos, como proliferação de insetos, ratos e outros animais que acabam representando um problema de saúde pública. Também não foi feito referência de que muitos desses resíduos poderiam ser evitados utilizando técnicas corretas na construção, evitando a necessidade de desmanchar e refazer, e isso deveria ter vindo com os conhecimentos proporcionados pelo curso.

[...] merecem destaque os conteúdos relativos às novas formas de organização e gestão dos processos produtivos e das novas relações sociais por estes determinadas, incluindo-se ai os novos processos de qualidade, não exclusivamente inscritos no âmbito da produtividade, mas principalmente no âmbito da qualidade de vida de toda as dimensões, compreendendo a preservação do ambiente; os conteúdos relativos aos novos instrumentos de gestão e controle do trabalho; as transformações que estão sendo propostas para a legislação trabalhista e previdenciária; as novas formas da organização da economia e dos trabalhadores como alternativas às antigas formas de enfrentamento das condições entre capital e trabalho; as novas demandas de educação geral e profissional para os trabalhadores; os impactos das novas tecnologia sobre a saúde a segurança em geral e no trabalho e assim por diante (KUENZER, 2001, p. 7).

A segunda questão descritiva - "Para você o curso contribuiu para o entendimento dos problemas ambientais gerados pela construção civil? Independente da resposta considera possível ou não fazer algo no seu ambiente de trabalho para diminuir esses problemas? " Trouxe na sua 
primeira parte uma igualdade (50\%) entre os que acharam que o curso contribuiu para o entendimento dos problemas ambientais gerados pela construção civil e os que entenderam que não.

Numa análise que Loureiro (2004) faz do relacionamento do homem com mundo podemos observar o quanto a interferência do ser humano nesse relacionamento e importante e como pode ser modificado a partir da educação:

Assim, pensa o ser humano em sua peculiaridade (atividade transformadora da natureza na
história, gerando cultura), na qual a relação "eu-mundo" se dá por mediações criadas na vida em
sociedade. Logo, em Educação Ambiental, segundo a perspectiva marxiana, pensar em mudar
comportamentos, atitudes, aspectos culturais e formas de organização, significa pensar em
transformar o conjunto das relações sociais nas quais estamos inseridos, as quais constituímos e
pelas quais somos constituídos, o que exige, dentre outros, ação política coletiva, intervindo na
esfera pública, e conhecimento das dinâmicas social e ecológica (LOUREIRO, 2004, p. 122).

Já na pergunta 17, no que tange a possibilidade dos entrevistados de contribuírem para minimizar problemas ambientais no trabalho, tão pouco são as considerações que passamos a apresentar na integra: "somente os problemas que já conheço, pois o curso em si muito pouco se comentou a respeito" (E1, 2014, p. 6); "Pouco material dado, em base em nosso setor de trabalho é educar o nosso colega a cuidar do meio ambiente" (E2, 2014, p. 6); “Sim" (E4, 2014, p. 6); “Nem tanto quanto devia, já faço o possível" (E5, 2014, p. 6); "Sim" (E6, 2014, p. 6); "Sim, manter o local de trabalho limpo e organizar os materiais contribui para isso" (E7, 2014, p. 6); "Fazendo a minha parte com consciência" (E8, 2014, p. 6); "Na minha opinião o curso não contribuiu com os problemas gerados pela construção civil, mas acho possível fazer algo" (E9, 2014, p. 6) e "Contratação de caçamba" (E10, 2014, p. 6).

A partir das respostas fornecidas, constata-se que realmente o curso trouxe pouco do entendimento da problemática ambiental, e da forma que as atividades da construção devem ser tratadas a fim de minimizar esses problemas e dando um aspecto de sustentabilidade no decorrer do curso, mesmo sendo previsto no item justificativa do Projeto Pedagógico do Curso (PPC), conforme segue:

Este é um curso para aperfeiçoamento de pessoal que atua em canteiro de obra compreendendo tecnologias relacionadas à construção civil. Abrange obras civis, mobilizando, de forma articulada, saberes e tecnologias relacionadas às atividades do profissional no canteiro de obras civis. O curso terá abordagem sistemática da gestão da qualidade, ética, segurança, conhecimento de materiais, normas técnicas, práticas construtivas e sustentabilidade (IFSul - PPC Mestre de Obras, 2012, p. 3).

Em uma terceira questão descritiva - "Que sugestão teria para que o curso contribuísse para uma formação mais consciente, com respeito às relações do homem com o homem e homem 
com a natureza?" Ao considerar as respostas dos entrevistados pode-se observar o quanto deficiente foi o curso nesse aspecto. Somente 7 pessoas (70 \%) responderam à pergunta com solicitações como: mais diálogo sobre o meio ambiente; contratação de ambientalistas para aulas de meio ambiente; enfatizar no próximo curso; uma disciplina sobre meio ambiente; vídeos, palestras sobre a questão ambiental; mais informações e aula sobre este assunto.

Apesar do PPC (2012, p. 5) ter em seu conteúdo programático uma disciplina intitulada "tecnologias da construção e meio ambiente" e ainda dividir essa disciplina em cargas horárias especificas: "tecnologia da construção - 40 horas" e "meio ambiente - 8 horas", que preveem o estudo dos "principais impactos ocasionados durante a construção", as respostas dos entrevistados deixam claro que existe necessidade de um aprofundamento maior na questão ambiental.

A grande maioria dos entrevistados (90\%) gostaria que o curso tivesse thes proporcionado mais conhecimentos sobre o ambiente e sua profissão, fato esse que pode ser comprovado pelo Gráfico 5.

Você gostaria que o curso tivesse proporcionado mais conhecimentos sobre o ambiente?

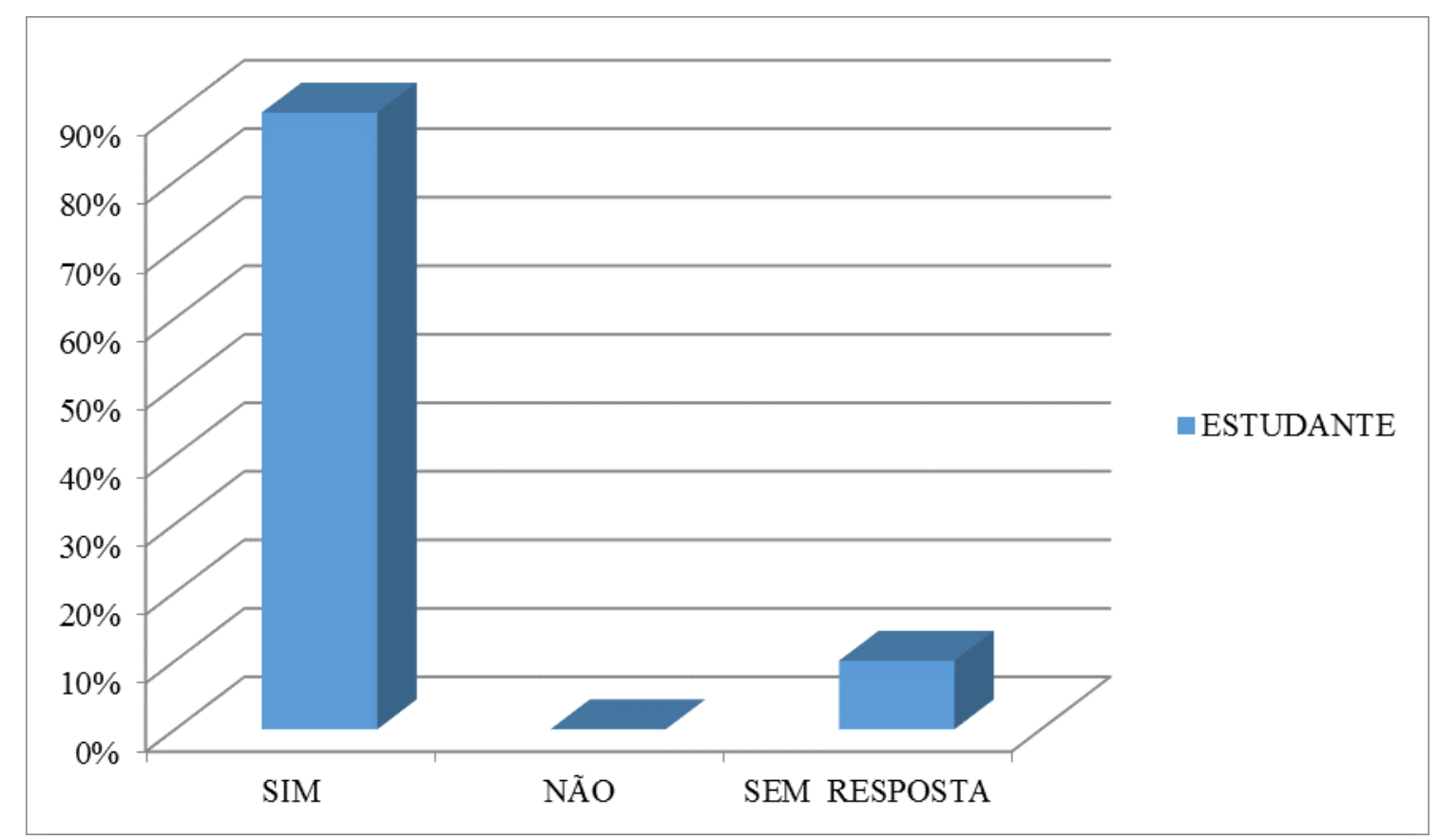

Gráfico 5: Percentual sobre a necessidade do curso ter proporcionado mais conhecimentos sobre ambiente Fonte: Autor (2016).

Retomando a Lei $\mathrm{n}$ a 9.795, de 27 de abril de 1999, em seus dois primeiros artigos e mais, no art. 10 que diz: “A educação ambiental será desenvolvida como uma prática educativa integrada, contínua e permanente em todos os níveis e modalidades do ensino formal" (BRASIL, Lei no 9.795/1999, art. 1ㅇ), complementada pelo inciso 1o desse artigo "A educação ambiental não deve ser implantada como disciplina específica no currículo de ensino".

E principalmente considerando as informações obtidas a partir da pesquisa concluímos que, embora esteja previsto no PPC do curso FIC do Pronatec - Área da construção civil de Mestre 
de Obras no Instituto Federal Sul-rio-grandense (IFSul), câmpus Pelotas, uma abordagem sobre o meio ambiente, a mesma é equivocada e pouco representativa. Isto porque na análise da legislação é possível constatar que a mesma não prevê uma disciplina específica tratando da problemática ambiental, mas sim "[...] uma prática educativa integrada e interdisciplinar, contínua e permanente em todas as fases, etapas, níveis e modalidades, não devendo, como regra, ser implantada como disciplina ou componente curricular específico (BRASIL, 2012, p. 70) ". Pouco representativa foi o que se contatou na análise da parte subjetiva da pesquisa na medida em que todos os entrevistados, mesmo concordando que receberam conhecimentos sobre a problemática ambiental, salientaram que deveria ter sido em maior quantidade, inclusive sugerindo outras atividades.

\section{CONCLUSÃO}

Como podemos observar e já mencionamos ao longo do texto, desde os primeiros ensinamentos profissionais, ainda no Brasil colônia, esse tipo de atividade esteve sempre ligado ao "saber fazer", ao trabalho braçal, a princípio sem a preocupação nem mesmo de um ensinamento de alfabetização. Só posteriormente, já em meados do século XX, o saber fazer uniu-se a educação propedêutica.

Mesmo que na atualidade, os próprios cursos FIC tenham em seus conteúdos programáticos, disciplinas propedêuticas, pela própria necessidade de entenderem algumas disciplinas técnicas, podemos observar que a preocupação com a formação de um profissional questionador, conhecedor de seus direitos e deveres, enfim de um cidadão, ainda continua sendo preciso atingir.

No modo de produção capitalista, onde a propriedade privada e a ganância se sobrepõem às necessidades dos seres humanos, gera contradições em vários setores, situação que não é diferente tratando-se da construção civil. Contradições essas que de acordo com Pouey (2012, p. 96) "começam numa extração desenfreada de matérias-primas da natureza, passam por um consumo de energia também assustador para a produção dos chamados materiais convencionais, industrializados e culminam com uma geração de resíduos".

O trabalho nos mostra que a formação educacional do trabalhador atual, além dos ensinamentos técnicos, também precisa de conhecimentos políticos, econômicos, sociais e intercultural que possibilitem uma visão crítica em relação o papel do ser humano envolvendo a lógica do acúmulo desenfreado do capitalismo. Marcelo Feres $(2015)^{5}$, ao ser recentemente questionado sobre a suposta dualidade no mundo do trabalho entre os que pensam e os que fazem em uma entrevista para o Boletim da Secretaria de Educação Profissional e Tecnológica do Ministério da Educação, informa o seguinte.

${ }^{5}$ Marcelo Feres, Secretário de Educação Profissional e Tecnológica do Ministério da Educação entrevistado no III Fórum Mundial de Educação Profissional e Tecnológica (III FMEPT), realizado de 23 a 26 de maio de 2015 em Recife/PE. 
No Brasil, a educação profissional sempre esteve associada a um conceito de formação estritamente relacionado ao fazer, refletindo uma cultura que segmenta a sociedade entre os que avançam para ensino superior e os que irão para o mundo do trabalho com as qualificações mínimas necessárias. No entanto, com os avanços científicos e tecnológicos, não faz mais sentido sustentar esta visão. A característica marcante da educação profissional e tecnológica é a associação entre teoria e prática. Mas para compreender a teoria é preciso que o processo formativo leve em consideração a base humanística, científica e tecnológica necessária, para que se possa desenvolver a dimensão prática do trabalho, a condição para iniciar uma carreira profissional e ainda a base para continuar os estudos em nível de graduação e pós-graduação (FERES, 2015, $s / p)$.

Constata-se, portanto, que no estudo de caso analisado envolvendo o Curso do Pronatec, dentro da área da construção civil de Mestre de Obras no Instituto Federal Sul-rio-grandense (IFSul), câmpus Pelotas, mesmo com indicativos de uma visão planetária e o esforço dos professores em desenvolver, com os alunos, aspectos críticos no que tange a área da construção civil e a problemática ambiental é bastante aquém do que o esperado pelos educandos.

O homem continua a utilizar a natureza como se dela não fizesse parte e como se os recursos fossem intermináveis, entretanto ela reage, muitas vezes apresentam dimensões catastróficas. Relativo a educação que por tanto tempo manteve-se compartimentada, continua gerando dificuldades para os educadores desenvolver um processo emancipatório e sistêmica com a visão de que os conhecimentos estão interligados e o ambiental é parte constituinte em todos eles. Fica o desafio que as ações de cada indivíduo fazem diferença para sustentabilidade planetária.

\section{REFERÊNCIAS}

BIAGINI, Jussara. Revisitando momentos da história do ensino técnico. Texto constitutivo da pesquisa realizada no curso de mestrado no Programa de Pós-Graduação em Educação: História, política, sociedade. São Paulo: PUC, 2005. Disponível em: <http://www.ichs.ufop.br/conifes/anais/EDU/edu1713.htm>. Acesso em 28 de julho de 2015.

BRASIL. Lei no 11.892, de 29 de dezembro de 2008. Institui a Rede Federal de Educação Profissional, Científica e Tecnológica, cria os Institutos Federais de Educação, Ciência e Tecnologia e dá outras providências. Diário Oficial (da) República Federativa do Brasil, 2008.

BRASIL. Lei no 12.513, de 26 de outubro de 2011. Institui o Programa Nacional de Acesso ao Ensino Técnico e Emprego (Pronatec); altera as Leis no 7.998, de 11 de janeiro de 1990, que regula o Programa do Seguro-Desemprego, o Abono Salarial e institui o Fundo de Amparo ao Trabalhador (FAT), no 8.212, de 24 de julho de 1991, que dispõe sobre a organização da Seguridade Social e institui Plano de Custeio, № 10.260, de 12 de julho de 2001, que dispõe sobre o Fundo de Financiamento ao Estudante do Ensino Superior, e no 11.129, de 30 de junho de 2005, que institui o Programa Nacional de Inclusão de Jovens (ProJovem); e dá outras providências. Diário Oficial [da] República Federativa do Brasil, 2011. 
BRASIL. Lei no 3.552, de 16 de fevereiro de 1959. Dispõe sôbre nova organização escolar e administrativa dos estabelecimentos de ensino industrial do Ministério da Educação e Cultura, e dá outras providências. Diário Oficial [da] República Federativa do Brasil, 1959.

BRASIL. Lei no 6.938, de 31 de agosto de 1981. Dispõe sobre a Política Nacional do Meio Ambiente, seus fins e mecanismos de formulação e aplicação, e dá outras providências. Diário Oficial [da] República Federativa do Brasil, 1981.

BRASIL. Lei no 9.795, de 27 de abril de 1999. Dispõe sobre a educação ambiental, institui a Política Nacional de Educação Ambiental (PNEA) e dá outras providências. Diário Oficial [da] República Federativa do Brasil, 1999.

BRASIL. Resolução no 2, de 15 de junho de 2012. Estabelece as Diretrizes Curriculares Nacionais para a Educação Ambiental. Diário Oficial [da] República Federativa do Brasil, № 116, Seção 1, págs. 70-71 de 18/06/2012.

CAMPOS, Luís Henrique de. Qualificação Profissional no Brasil: considerações para políticas públicas mais efetivas. São Paulo, 2012.

CEOTTO, Luiz Henrique. A Construção Civil e o Meio ambiente: 1a parte; 2a parte; 3a parte. Notícias da Construção, Ed. 51 a 53, São Paulo, SP, 2008. Disponível em: <http://www.sindusconsp.com.br/secoes.asp?subcateg=74\&categ=16>. Acesso em: 22/06/ 2015.

COSTA, Fernanda Cosme da. O Programa Nacional de Acesso ao Ensino Técnico e Emprego (PRONATEC) e a educação escolar da classe trabalhadora, 140 f. 2015. Dissertação (Mestrado Profissional em Educação Profissional em Saúde) - Fundação Oswaldo Cruz, Rio de Janeiro, 2015.

CUNHA, Luiz Antônio. O ensino industrial-manufatureiro no Brasil. Revista Brasileira de educação. n. 14, p. 89-107, mai./ago. 2000.

E1 - Estudante 1: questionário [10 dez. 2014, 6 p.]. Aplicador: O autor. Pelotas/RS: s.e., 2014.

E2 - Estudante 2: questionário [10 dez. 2014, 6 p.]. Aplicador: O autor. Pelotas/RS: s.e., 2014.

E3 - Estudante 3: questionário [10 dez. 2014, 6 p.]. Aplicador: O autor. Pelotas/RS: s.e., 2014.

E4 - Estudante 4: questionário [10 dez. 2014, 6 p.]. Aplicador: O autor. Pelotas/RS: s.e., 2014.

E5 - Estudante 5: questionário [10 dez. 2014, 6 p.]. Aplicador: O autor. Pelotas/RS: s.e., 2014.

E6 - Estudante 6: questionário [10 dez. 2014, 6 p.]. Aplicador: O autor. Pelotas/RS: s.e., 2014.

E7 - Estudante 7: questionário [10 dez. 2014, 6 p.]. Aplicador: O autor. Pelotas/RS: s.e., 2014.

E8 - Estudante 8: questionário [10 dez. 2014, 6 p.]. Aplicador: O autor. Pelotas/RS: s.e., 2014.

E9 - Estudante 9: questionário [10 dez. 2014, 6 p.]. Aplicador: O autor. Pelotas/RS: s.e., 2014.

E10 - Estudante 10: questionário [10 dez. 2014, 6 p.]. Aplicador: O autor. Pelotas/RS: s.e., 2014.

FAUSTO, Boris. História do Brasil. São Paulo: Editora da USP, 1994.

FREIRE, Paulo. Pedagogia do oprimido. 17ạ. ed. Rio de Janeiro: Paz e Terra, 1987.

FRIGOTTO, Gaudêncio. Educação e Trabalho: bases para debater a Educação Profissional e Emancipadora. Perspectiva. Florianópolis, v.19, n.1, p.71-87, jan. /jun. 2001. 
GARCIA, Sandra Regina de Oliveira. O fio da história: a gênese da formação profissional no Brasil. Núcleo de Estudos da UFMG. Belo Horizonte: Unisinos, n. 2, set 2000, disponível em < http://www.anped. org.br/reunioes/23/textos/0904t. PDF>, acesso em 26/04/2016. p. 01-18.

GRÜN, Mauro. A outridade da natureza na educação ambiental. In II Simpósio Gaúcho de Educação Ambiental. Erechim, 2002.

GUTIÉRREZ, Francisco; PRADO, Cruz. Ecopedagogia e cidadania planetária. 4. ed. São Paulo: Cortez, 2008.

IFSul. Projeto Pedagógico Do Curso (PPC) de Mestre de Obras - Pronatec. Pelotas, 2012.

KUENZER, Acácia. As mudanças no mundo do trabalho e a educação: novos desafios para a gestão. São Paulo, Cortez, 2001.

LIMA, Marcos Ricardo de. Pronatec - programa nacional de acesso ao ensino técnico e emprego: Uma crítica na perspectiva marxista. Estudos do Trabalho. Marília, ano V, n. 11, 2012.

MACHADO, Maria Margarida; GARCIA, Lênin Tomazett. Passado e presente na formação de trabalhadores jovens e adultos. Revista Brasileira de Educação de Jovens e Adultos. Salvador, v.1, n.1, p.45-64, 2013.

MEC boletim Setec/MEC, no 1, 03 jul. 2015 disponível em: $<$ http://redefederal.mec.gov.br/noticias/784-secretario-fala-dos-avancos-e-desafios-daeducacao-profissional-e-tecnologica-no-brasil2> acesso em 10/07/2015.

MEC. 1909 - 1914: 105 anos rede federal de educação profissional e tecnológica. Disponível em: $<$ redefederal.mec.gov.br> acesso em 13/07/2015.

MEC. Portal do Pronatec. Disponível em: <pronatec.mec.gov.br> acesso em 12/07/2015.

MEDEIROS NETA, O. M.; NASCIMENTO, J. M.; RODRIGUES, A. G.G. Uma Escola para aprendizes artífices e o Ensino Profissional primário gratuito. Holos. Ano. 28. v. 2. p. 96-104. 2012.

MENDES, Henrique. A construção civil e seu impacto no meio ambiente. Portal do meio ambiente, 2013. Disponível em < http://portal.rebia.org.br/meio-ambiente-urbano/6877-a-construcaocivil-e-seu-impacto-no-meio-ambiente> acesso em 13/07/2015.

MORIN, Edgar. A cabeça bem-feita: repensar a reforma, reformar o pensamento. 8. Ed. Rio de Janeiro: Bertrand Brasil, 2003.

PORTAL do LICEU DE ARTES E OFÍCIOS. S.d. Disponível em: <http://www.liceudearteseoficios.com.br/a-instituicao/historia/>, acesso em 26/04/2016.

POUEY, João F. F. Educação ambiental no curso de Técnico de Edificações - IFSUL Campus Pelotas: desafios e possibilidades da educação emancipatória nos cursos técnicos, 132 f. 2012. Dissertação (Mestrado em Educação Ambiental) - Fundação Universidade de Rio Grande (FURG), Rio Grande, dez. 2012.

RODRIGUES, José. Celso Suckow da Fonseca e a sua "História do ensino industrial no Brasil". Revista Brasileira de história da educação. Maringá, no 4, p. 47-74, jul. /dez.2002.

SANTOS, Simone Valdete dos. O ser e o estar de luto na luta: Educação profissional em tempos de desordem - Ações e resultados das políticas públicas do PLANFOR / Qualificar na cidade de Pelotas/RS (2000 - 2002). 2003. v. 1, 384 f. Tese (Doutorado em Educação) - Universidade Federal do Rio Grande do Sul, Porto Alegre, ago. 2003. 